\title{
Vinícius de Moraes e a morte
}

\author{
Seleste Michels da Rosa*
}

\begin{abstract}
Resumo: O presente trabalho pretende olhar a poética de Vinícius de Moraes buscando as visões representadas da morte e de que forma ela se manifesta nessa poética. Para analisarmos as visões da morte que Vinícius nos apresenta, usaremos o texto de Edgar Morin, $O$ Homem $e$ a Morte, e complementarmente a isso, as visões das escolas literárias sobre o tema.
\end{abstract}

\begin{abstract}
The present work aims at looking at Vinícius de Moraes's poetics to identify the represented visions of death and the way these visions are manifested in Vinícius de Moraes's poetical works. To analyze the visions of death that Vinícius de Moraes presents, we will resort to Edgar Morin's $O$ Homem $e$ a Morte and to relevant criticism on this subject.
\end{abstract}

Palavras-Chave: poesia; morte; Vinícius de Moraes.

Keywords: poetry; death; Vinícius de Moraes.

Percebemos mediante a leitura da obra completa de poesias de Vinícius que o poeta conhecido por suas canções de amor tem uma obsessão bem diversa daquela pela qual ficou conhecido: a morte. Por isto, esse ensaio pretende ver como o poeta Vinícius de Moraes trata este tema, e isso também revela o quanto a crítica comum não estava de todo equivocada quando liga estreitamente o poeta ao amor, pois a morte que o poeta apresenta é bastante ligada à temática amorosa. Conforme Gomes ([s.d], p.28), isso é comum na poesia metafísica: "Muitas vezes, entrelaçado ao tema do amor, surge o da morte, tanto em poemas profanos como religiosos [...]". Sabemos que na obra de Vinícius há tanto poemas religiosos quanto profanos e veremos como essa ligação se repete nos dois tipos de suas poesias.

Através desta preocupação com o tema da morte, o poeta adentra um estilo de poesia metafísica, já que "o que caracteriza a metafísica é a transcendência.” (FREICHEIRAS, 2001, p. 62). E o poeta parece tratar exatamente deste lugar onde o concreto sozinho não pode dar conta da explicação do mundo. O lugar onde isso se mostra mais evidente é a hora da morte, o momento sublime onde um indivíduo deixa de estar em seu corpo. É nesse momento que vemos o ser superar o ente, ou seja, o ser humano é mais universal nesta hora comum a todos, por isso supera sua condição de ente, isto é, singular e individual. Assim, a relação com essa temática busca a essencialidade do humano. Conforme afirma Morin (1988, p. 31): "este horror engloba realidades aparentemente heterogêneas: a dor do funeral, o terror da

\footnotetext{
* Seleste Michels da Rosa é graduada em Letras pela UFRGS, especialista em Literatura Brasileira pela PUCRS. Atualmente cursa o mestrado em Literatura Brasileira na UFRGS, sendo bolsista do CNPq.
} 
decomposição do cadáver, a obsessão da morte. Porém, dor, terror e obsessão têm um denominador comum: a perda da individualidade.". Sendo assim, na morte, nos entrosamos em um sentimento coletivo, que tende mais à espécie do que ao sujeito e isso nos põe em conflito direto com a idéia de morte. De uma leitura atenta de sua obra podemos ver o quanto o poeta trata a morte de maneira conflituosa, ora como fuga dos desejos incessantes da carne, ora como apavorante fim da doce vida; mas é perceptível que em ambas situações essa temática está ligada ao desejo, como castigo ou como fim dele e nos poemas do fim da vida, a uma certa plenitude do amor verdadeiro.

Quanto à classificação categórica do tratamento da morte, temos que as estruturas formais e linguiísticas usadas pelo poeta são características da escola simbolista: o uso repetido do branco, das brumas, da névoa, o apelo à sonoridade, às cores, enfim a todos os sentidos. Também vemos o entrosamento com a natureza, que ora é pacífica e acolhedora, ora sombria e cheia de mistérios. Contudo, cremos que, principalmente em sua relação com a morte, vemos uma leve tendência barroca de dilaceramento entre a busca pelo paraíso cristão e a busca pelo desejo sexual, ligado à vida. Assim, por vezes ele aspira à morte que o livrará do pecado, outras vezes ele a teme como fim de seus prazeres, e talvez o início de seu martírio.

Percorreremos a obra de Vinícius, no que for possível, cronologicamente, pois percebemos uma mudança em sua visão de mundo e de vida e morte ao longo de sua existência. Os primeiro poemas são bem ligados a uma ótica católica, primeiramente como salvação e elevação depois com uma culpa cristã muito presente. Já nos poemas finais, a morte, diferentemente, é vista como um sono, algo mais tranqüilo; ou um encontro com as coisas verdadeiras.

Nos primeiros poemas é evidente a ligação do poeta com a corrente dos católicos, seus contemporâneos no Brasil, e o mesmo se dá com a temática abordada, também comum a eles. A morte é tema bastante presente na poética de Schmidt, conforme Bastide (1997, p. 109): “a morte é um tema multiforme em sua obra. Em geral ela se apresenta como a grande consoladora, aquela que lhe dará o grande descanso, é ponto de chegada.”. Em Vinícius, isso acontece só nos poemas iniciais, onde o contato com o divino é forte e nos poemas finais, onde a morte é aspirada por ser o lugar dos amores verdadeiros. O poema "Purificação" é extremamente religioso e vinculado a esta primeira etapa. A primeira estrofe fala de uma chegada a Deus através da contemplação da natureza, se assemelhando aos textos românticos. Nesse poema é através da natureza que se vê a luz, a essência, e se encontra a divindade: Deus é a correspondência espiritual da natureza, assim como também postulam os simbolistas, 
como mostra o verso 14, "e na natureza ouvi tua voz." (MORAES, 1968, p. 88).Conforme SWEDENBORG (apud GOMES, 1985, p. 15), a ligação com Deus se dá através da natureza:

todas as coisas que existem na natureza, desde o que há de menor ao que há de maior são correspondências. A razão para que sejam correspondências reside no fato de que o mundo natural, com tudo o que contém, existe e subsiste graças ao mundo espiritual, e ambos os mundos graças à Divindade.

A imagem da morte é cristã: uma luz que cresce e toma conta da visão do moribundo, como mostram os versos 11 e 12, "A luz cresceu, cresceu interiormente/ E toda me envolveu" (MORAES, 1968, p. 88). Por fim, temos a ascendência do eu lírico, nos versos 22 e 23, “A minha voz subiu até ti, Senhor/ E tu me deste a paz" (MORAES, idem, ibdem). Enfim, o eu lírico pede que Deus guarde seu coração, sua alma e seu espírito, num pedido por salvação, mostrando por que Deus deve salvá-lo em cada verso consecutivo ao pedido, como mostram os versos 26, 28, 30 e 31. Através deste poema lemos uma das visões do eu lírico sobre a morte: seu julgamento, seu pedido por salvação, sua ascensão, seu encontro com Deus. O poema traz alguns traços de simbolismo na linguagem, no falar de luz, de céu, de flores, de ascensão, de música, como mostram os versos 15 e 16, "Pássaros cantaram no céu/ Eu olhei para o céu e cantei, e cantei" (MORAES, idem, ibdem); mas não é um poema tipicamente simbolista porque não se trata de um espiritualismo tendente ao universal, mas fortemente ligado ao imaginário cristão, ou mais amplamente, das religiões de salvação ${ }^{1}$ onde o êxtase, a comunicação imediata com o deus através de um ritual específico, garante a salvação, a ressurreição após a morte, ou seja, livra o homem de seu maior temor.

Já em "O Cadafalso" temos uma visão de perdição, ainda dentro da ótica religiosa, onde o amor carnal o leva a perdição. Neste poema é perceptível a temática recorrente do poeta: o sexo, neste contexto, visto como gerador de pecado e culpa. O eu-lírico é culpado, como mostra o primeiro verso: "Eu caí de joelhos diante do amor transtornado do teu rosto" (MORAES, 1968, p. 138), a ação é do eu-lírico, não é a mulher que o seduz, ele se entrega; o que evidencia a ação do eu lírico é o fato de o poema estar centrado na primeira pessoa. Toda a menção ao sexo é feita com imagens negativas de choro, perda da pureza e morte. Por causa dessa culpa, ele é condenado. O poeta sente culpa não só por incorrer no pecado da carne, mas também por suas atitudes sexuais frente às mulheres, já que a condenação não é trazida por Deus, mas por uma mulher, "E veio então uma mulher como uma visão sangrenta de revolta" (MORAES, 1968, p. 138). Mas só a primeira condenação é feita por ela, em seguida há a segunda condenação que é representada por sua ida ao inferno, como se, para castigá-lo, não fosse suficiente uma morte dolorosa, ainda é necessária a danação. Partindo desta condenação

\footnotetext{
${ }^{1}$ Conforme MORIN, Edgar. O homem e a morte. Portugal: Europa-America, 1988.
} 
podemos ver uma tendência barroca da culpa levada ao extremo, da perdição, do inferno sempre presente e do Deus punitivo que ronda atrás de algum deslize para condenar os seres ao inferno. Sendo assim, concordamos com Bandeira (apud SILVA, 2006, [s.p.]):

Sua obra [de Vinícius de Moraes] apresenta um artista de diversificado estilo, de grande força criadora, a quem Manuel Bandeira se referiu da seguinte forma: ele tem o fôlego dos românticos, a espiritualidade dos simbolistas, a perícia dos parnasianos (sem refugar, como estes as sutilezas barrocas), e finalmente, homem bem do seu tempo, a liberdade, a licença, e o esplêndido cinismo dos modernos. (1998, p. 80)

A síntese de todas essas escolas resulta também num tratamento múltiplo da temática da morte. Além de salvação ou perdição, a morte é também percebida como conseqüência imediata do desejo sexual, conforme o versículo bíblico "Romanos 6:23", "porque salário do pecado é a morte" ${ }^{2}$. E o eu-lírico, vê, neste momento, uma relação intrínseca entre o desejo e o pecado. Posteriormente, essa relação negativa vai se esvaindo, dando lugar a uma sexualidade menos reprimida e se desligando da idéia da morte.

Já no poema "A mulher na noite", o eu-lírico não tem ação, ele simplesmente é seduzido e preso. A inércia do poeta é clara: "Contudo a volúpia entrou em mim e ulcerou a treva nos meus olhos./ Eu estava imóvel” (MORAES, 1968, p. 139). O eu-lírico se resguarda da culpa, mostrando que não tinha intenção de pecar, assim como no poema anteriormente mostrado, onde ele diz: "E me deixava parado, vazio para a contemplação da tua face" (MORAES, 1968. p. 139). Seu único deslize é deixar a volúpia entrar, mas já é o suficiente para o maior dos martírios; a natureza vem para castigá-lo. Pode-se dizer que o poeta se deixa morrer. Conforme Morin (1988, p. 39) “a afirmação da "consciência coletiva” está tão presente na consciência individual que o sacrílego, mesmo involuntário, executa de per si a condenação à morte implicada na violação do tabu.”. Então o eu-lírico está tão imbuído de culpa que se deixa aprisionar e em conseqüência deste aprisionamento, temos sua morte. Neste poema, o próprio Deus, regulador da natureza, quem vem cobrar a dívida do pecador. Desta forma, esse poema se mostra mais religioso que o outro, apesar das cenas sórdidas herdadas de um neo-simbolismo, no Brasil representado por Augustos dos Anjos, marcado por figuras abjetas como a urina, típicos da lírica moderna. "Aquilo que era, até então, desqualificado, permitido só nos gêneros literário inferiores e nas zonas marginais da arte plástica, vem elevado a um valor expressivo metafísico. [...] O grotesco deve aliviar-nos da beleza e, com sua "voz estridente", afastar sua monotonia." (FRIEDRICH, 1978, p.33). Dessa forma, a morte se apresenta não só como a perdição do espírito, mas como morte corpórea também, isto é, aqui temos mais valorizada a maneira como o corpo perde as condições para a

\footnotetext{
${ }^{2}$ http://www.bibliaonline.net/scripts/bol.cgi.
} 
vida e transita para morte; temos a angústia, o sufocamento, enfim, o sofrimento do eu-lírico para essa transição, como mostram os verso de 10 a 16. Mas temos uma vida pós-morte diferente do segundo poema anteriormente citado onde seu destino era perecer no inferno. Em "Mulher na noite", não temos uma punição depois da morte em decorrência do pecado, o castigo é a própria morte e a maneira sofrida de morrer. $\mathrm{O}$ verso final deixa claro o vazio, " $\mathrm{E}$ não havia mais vida na minha frente" (MORAES, 1968, p. 139). Chegamos a uma morte que leva ao nada. Portanto, o poeta parte de um certo realismo para atingir o transcendente. Conforme Gomes ([sd.], p.28), “o realismo é viril, irreverente, por vezes até rude, mas nunca materialista, pois inclui também as realidades do espírito". Então, mesmo que este poema fique mais centrado nas sensações corpóreas do eu-lírico, ele não é um poema materialista, pois se mantém ligado ao transcendente como mostram principalmente os versos 12, 17 e 18 .

Já “A música das almas", do mesmo livro que "Mulher na noite", retoma a morte como salvação. É interessante trazê-lo à discussão pela maneira como ocorre a morte, similar a do poema anterior. Este compara a passagem da vida para a morte com uma tempestade, a chegada da morte com o céu nublando e o vento soprando forte e desta maneira o poema cria uma tensão. Logo chegamos ao clímax, "os braços das árvores que estrangulam a terra" (MORAES, 1968, p. 142), ou seja, o sofrimento do momento da morte é retomado; novamente como uma falta de ar crescente. Um dado biográfico que pode elucidar a leitura dessa figura é que Vinícius de Moraes sofria de asma desde criança, uma doença que causa a sensação e o risco de morte por sufocamento. Sendo assim, o poeta pode ter transmutado essa experiência empírica para a experiência artística e a relacionado com a morte. Temos esse tema também tratado na "Balada do enterrado vivo", e no poema "Vinte anos", o que indica uma recorrência ao tema. Isso pode elucidar um pouco a leitura da morte em sua obra poética como um temor, uma realidade que se mostra presente e próxima a cada momento. Contudo, depois da "passagem" temos a claridade, a paz, "Depois veio a claridade, o grande céu, a paz dos campos..." (MORAES, 1968, p. 142) A partir daí lemos que a alma pôde sair do suplício e se perceber mais tranqüila. Mas ainda há os que choram pelo caminho, chamando por aqueles que se foram. A maior presença da morte é nos rituais de funeral, segundo BACON (apud MORIN, 1988, p.27), "as pompas de morte excedem o fenômeno da morte". Sendo assim, a preocupação não é só com a morte em si, mas também com os que ficam e com quão tristes estes ficam. Este é o primeiro poema no qual a morte é vista por dois ângulos, do morto e dos que ficam. Estes, apesar da alma ter sido salva e tudo parecer bem, ainda choram olhando para o céu. 
Em "O Nascimento do Homem”, há novamente a idéia de que o desejo é o causador da morte, como em "A Mulher na Noite". Novamente o desejo vem da mulher, mas desta vez ela é sedutora, como mostram os versos, "Vinha dela uma fala de amor irresistível/ Um chamado como uma canção noturna na distância” (MORAES, 1968, p. 139.). A partir daí há todo um envolvimento sexual do eu-lírico com a mulher impura ("Oh, como era bela! era impura - mas como ela era bela!” (MORAES, 1968, p. 139.)) e a partir do verso 33, iniciam

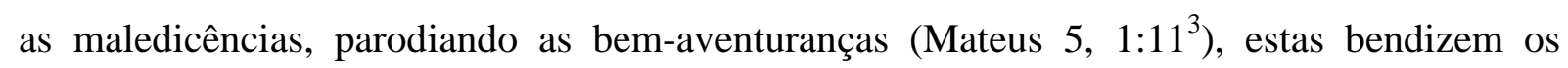
puros, aquelas maldizem os impuros, os sedutores e os seduzidos, os que se deixam envolver pela luxúria. O verso 39 fala de lírios, na obra de Vinícius associado ao falo e à sexualidade; "lírios nascidos da face lívida da morte", logo temos de forma mais evidente a crença de que o desejo é o causador da morte.

O poema "A morte" fala da espera pela morte. Ela, que é sempre esperada, por medo ou vontade. Neste poema a posição do eu-lírico a respeito da morte é totalmente diversa, ela já não tem aquele aspecto punitivo, ela é simples conseqüência da vida e é preciso não ter medo da vida para viver até a morte. Parece que agora o poeta quer assumir o risco de morrer para viver, está mais conformado com vida que ele deseja e mais confortável com suas opções, por isso a morte passa a ser só mais um estágio pelo qual todos vão passar e por isso todos esperam. Segundo Sócrates (apud MORIN, 1988, p. 230.), “não sabendo se a morte é um bem ou um mal, um nada ou um tudo, só devemos agarrar-nos ao bem da vida, que este é certo.”. Este livro, "O encontro do cotidiano", segundo alguns autores, marca uma mudança na obra de Vinícius. Parece-nos que essa mudança é o reflexo de uma modificação na sua própria ideologia. $\mathrm{O}$ poeta está chegando a uma idade de maior maturidade, tem sua primeira filha e, de certa maneira, se desvincula de forma mais definitiva de sua família natural, para além do distanciamento geográfico; por isso parece natural que ele perca parte de sua identificação com a religiosidade que lhe era imposta pela família. Obviamente ele nunca perderá sua formação católica, mas a partir dessa obra, em sua obra, ela não aparecerá tão fortemente. Vemos em “Quatro sonetos de meditação II" uma mudança grande no tratamento da morte. Nele o amor, antes visto como causador da morte, é o redentor, o que salva o poeta da morte que o espreita. É uma relação mais serena, provocada pelo amadurecimento de sua relação com a mulher, figura antes ligada as suas noções de pecado e morte. A relação amorosa mais estável faz com que o eu-lírico creia que uma mulher realmente o ame e isso faz com que ele esteja salvo; pois mesmo que a morte chegue, ela sentirá desalento, conforme

\footnotetext{
${ }^{3}$ http://www.bibliaonline.net/scripts/bol.cgi
} 
o verso 2. Esse sentimento de conformidade e tranqüilidade em relação à vida e à morte parece difícil de enquadrar em alguma tendência literária à qual Vinícius seja vinculado, isto é, romantismo ou simbolismo; os românticos nunca alcançam essa relação de completude com a mulher amada, os simbolistas, também não se enquadrariam nessa ideologia, estariam mais contemplados com suas imagens sinestésicas como a do verso 6, onde diz, "Me ama como a chama ama o silêncio" (MORAES, 1968, p. 255.) ou quando diz, no verso 3 e 4, "Da árvore jovem que não ouve o vento/ Inconstante e fiel, tardio e doce" (MORAES, 1968, p. 255.). Segundo Gomes (1985, p. 17): “a fusão, portanto, de diferentes sensações, as chamadas sinestesias, é um esforço para recuperar a linguagem original, aquela em que a palavra, mais do que simples representação dos objetos é também coisa ela própria.”. Essa é uma característica atribuída pelo autor à estética simbolista.

No poema "Epitáfio", vemos uma associação interessante; a do sol como ser vivente e, portanto, passível de morte. Parece-nos que o eu-lírico quer se comparar ao sol, que quer a forma de todas as mulheres e pretende morrer no mar. Aliás, o mar é uma constante na poesia de Vinícius, sempre figurando como um lugar desejado e prazeroso e nesse poema, o poeta parece levar sua morte para o mar, a fim de amenizá-la como simples parte do percurso. $\mathrm{O}$ mar é visto muitas vezes como esse tipo de morte tranqüila, como acontece também nos poemas "Mar, Azul e Branco" e "Versos Soltos no Mar", por exemplo. Sendo assim, percebemos que neste período de sua escrita, principalmente, o mar esteve muito ligado à idéia de morte, mas uma morte tranqüila e simples conseqüência da vida. Isso nos leva a ver algumas palavras que são bastante corriqueiras na obra de Vinícius, como o mar, já exemplificado, a cor roxa e também os lírios. Segundo Friedrich (1978, p.45), "para se penetrar a alma de um poeta, tem-se de procurar aquelas palavras que aparecem mais amiúde em sua obra. A palavra delata qual é sua obsessão.”. Outra palavra bastante presente e também ligada à morte é "roxa" que, por exemplo, aparece no poema "Tarde" onde o poeta fala, "Na hora dolorosa e roxa das emoções silenciosas" $\left(\right.$ MORAES $^{4}$ ); o roxo é também sempre uma noção de tempo, um tempo de término, como mostra o poema "A última parábola", onde o poeta diz, "No céu um dia eu vi - quando? era na tarde roxa" (MORAES, idem). O poema "Alba" também fala na "tarde roxa". Esta parece ser a cor predileta do eulírico já que no poema "Elegia Lírica" ele afirma isso, "E se eu lhe perguntar qual a cor mais bonita ela não dirá que é a roxa porém brique." (MORAES, idem) Já no poema "Marinha", o roxo aparece mais diretamente atrelado a morte, "E as ondas de pontas roxas/ Vão e vêm,

\footnotetext{
${ }^{4}$ In: http://www.viniciusdemoraes.com.br/poesia/sec_poesia_view.php?busca=tarde\&acao= buscar\&id=13\&id_tipo=1\&back_page $=1,25 / 09 / 2007$
} 
verdes e esquivas/ Vagabundas, como frouxas/ Entre vivas!” (MORAES, idem). O "Dicionário de Símbolos" de (CHEVALIER, 1990, p. 961) define o violeta como cor da "passagem outonal da vida para a morte" e ainda "do segredo: atrás dela realizar-se-á o invisível mistério da reencarnação ou, ao menos, da transformação" Além de ser interpretada como "cor da temperança, equilíbrio entre o céu e a terra, da paixão e da inteligência.".

Outra palavra que aparece muitas vezes é o lírio, ligado à sexualidade e à virilidade; só em alguns momentos com menção à morte, principalmente quando o poeta liga o desejo sexual ao castigo através da morte como no poema "Sonoridade". Também encontramos lírios no poema "Alba", "Alba, no canteiro dos lírios estão caídas as pétalas de uma rosa cor de sangue" (MORAES ${ }^{5}$ ) e no poema "Nascimento de um Homem", no verso final. A expressão foi encontrada em quinze poemas, sempre ligados a essa idéia. São eles, além dos supracitados, "Olhar para trás", "O escravo", "Variações sobre o tema da essência”, "Ariana, a mulher", "A mulher que passa", "Sonata do amor perdido", "Brusca poesia da mulher amada", "Cemitério na madrugada", "Idade Média”, "Solilóquio", "Soneto de carta e mensagem" e "Lápide de Sinhazinha Ferreira". É interessante perceber que esses poemas nem sempre têm a temática da morte, em alguns o lírio é relacionado ao falo e ao desejo; mas em muitos há associação com a morte. Vimos então que o poeta tem a liberdade de fazer novas associações simbólicas, internas a sua poética como afirma Wilson (1987, p. 21), “símbolos da escola simbolista são, via de regra, arbitrariamente escolhidos pelo poeta para representar suas idéias.”. Em nossa análise dessa poética pudemos encontrar repetidamente só estas palavras e as três são, em maior ou menor escala, ligadas à temática da morte o que nos faz crer que este é um dos temas preponderantes em sua poética.

Posteriormente, temos alguns poemas tratando de temas de guerra, e conseqüentemente de morte, como "Balada dos Mortos dos Campos de Concentração", que fala sobre a impressão dos cadáveres despejados e despojados para apodrecerem sem identidade e sem nada que os dê status de sujeito. Segundo Morin (1988), a morte em estado de guerra perde todos os traços de individualidade, o sujeito se perde na coletividade, na massa que o leva a enfrentar o medo da morte e se expor ao risco dela. Sendo assim, a morte terrível e temível só volta depois do fim da guerra quando se volta à consciência individual e se percebe a perda dos que não voltaram. Nesse poema, o autor adota uma visão nada espiritual, nem sentimental, para ver a morte. Ele faz dessa atitude poética uma maneira de denúncia da crueldade e da falta de humanidade dos atos que geraram aquelas mortes. Neste

\footnotetext{
${ }^{5}$ In: http://www.viniciusdemoraes.com.br/poesia/sec_poesia_view.php?busca=alba\&acao= buscar\&id=60\&id_tipo=1\&back_page $=1,25 / 09 / 07$
} 
momento, o poeta sai de sua aparente alienação para tomar uma posição política e principalmente humanitária em sua obra. O poeta vê a morte neste momento como um ato vil que iguala todas as pessoas e, neste caso, lhes tirando a dignidade. A morte é vista de maneira mais crua e carnal neste poema a fim de criar o impacto objetivado por ele.

Por fim, seus poemas ainda falam de morte, mas cada vez mais esparsamente até que em seu cancioneiro ela apareça muito pouco e de maneira totalmente diferente. Por exemplo, em "A hora íntima", o poeta brinca com a hora de sua morte e pergunta por quem lhe pagará o enterro se ele morrer de amores. O eu-lírico é um poeta que ama, mas parece muito solitário já que não encontra quem lhe pague o enterro apesar de morrer de amores; parece que o poeta teme morrer sem encontrar seu amor verdadeiro, enfim, a mulher ideal. Sua busca durante toda a vida, apesar de ter muitas a chorar por sua morte. Também é evidente que o poeta crê ter muitos amigos, pois eles estão bem presentes em sua descrição do enterro. Segundo Morin (1988), sempre houve uma preocupação grande em chorar, ou em se alegrar com a morte, dependendo da cultura, mas não se mostrar indiferente em relação à ela, por consideração ao morto. "Assim a ostentação da dor, própria de certos funerais, destina-se a provar ao morto a aflição dos vivos, a fim de garantir a benevolência do defunto." (MORIN, 1988, p.27). Enfim, o poeta assume uma visão irônica e tranqüila em relação à morte, não mais tratada de forma romântica e idealizada. Neste poema surgem os aspectos burocráticos e cerimoniosos que trazem a morte, como o pagamento do enterro nos versos finais e a sugestão do pedestal nos versos de 33 a 35 . A busca do amor verdadeiro fica evidente nos versos 55 e 56, onde o poeta questiona quem, de todas aquelas que estão presentes e às quais amou, terá de ser arrancada. Enfim, ele quer saber qual é seu amor para além da morte, sua mulher ideal. O poeta está chegando aos quarenta anos e ainda crê que não tenha encontrado sua companheira para toda a vida. Esse é um poema bastante moderno, com um tom irônico bem presente.

Já em "O soneto da hora final", percebemos novamente uma idealização em face da morte, um lugar onde se estará em plenitude com o ser amado, mas ainda é um lugar sombrio, de tristeza e nostalgia. Desta forma o poeta mostra uma conformação com a vida, mostra que gosta de viver, por isso em sua morte haverá nostalgia, mas também será um lugar de tranqüilidade expresso pela palavra "jardins". Sendo assim, vemos uma certa circularidade do tratamento da morte na poética de Vinícius. No início, em seus poemas mais religiosos, podemos ver essa conformação com a morte vista como elevação da alma e salvação divina. Num período intermediário percebemos o medo da morte e principalmente o medo do castigo que poderá vir com ela, ainda numa ótica bastante religiosa, mas já se afastando para o pólo da contraposição, ou seja, do pecador. Passamos depois por uma fase mais engajada, que vê a 
morte com crueldade, para atingir o impacto de denúncia, como em "A balada dos mortos em campo de batalha" e ainda por uma fase mais moderna, onde a ironia domina também o tratamento com a morte. Por fim, voltamos a uma visão pacífica da morte, contudo não mais vista como salvação, mas como simples etapa de vida, com algum ganho positivo.

Logo, a visão da morte pelo poeta se modifica ao longo de sua obra, de certa forma relacionada com o seu amadurecimento e com a mudança de suas convicções. Ao iniciar sua carreira literária, ele estava bastante ligado à casa da família e suas crenças religiosas, logo a seguir, entra em conflito com estas crenças, fazendo com que o eu-lírico entre também em conflito com a visão de sua própria morte, principalmente com o medo dela, que seria sua perdição. Por fim, na maturidade, o poeta alcança uma nova visão serena da morte, onde encontrará seu verdadeiro amor e viverá em paz, salvo de sua busca constante pelo amor verdadeiro.

\section{Referências}

BASTIDE, Roger. Estudo sobre a poesia religiosa brasileira. In: Poetas do Brasil.

São Paulo: Editora da Universidade de São Paulo/ Duas Cidades, 1997.

CHEVALIER, Jean. Dicionário de símbolos: mitos, sonhos, costumes, gestos, formas, figuras, cores, números. Rio de Janeiro: J. Olympio, 1998.

FREICHEIRAS, Marta Luzie de Oliveira. Para além da metafísica está a mística. In: Em Torno da Metafísica. Rio de Janeiro: 7 Letras, 2001.

FRIEDRICH, Hugo. Estrutura da lírica moderna (da metade do século XIX a meados do século XX). São Paulo: Livraria Duas Cidades, 1978.

GOMES, Aíla de Oliveira. Introdução. In: Poesia Metafísica. São Paulo: Companhia das Letras, [s/d].

GOMES, Álvaro Cardoso. A estética simbolista. São Paulo: Cultrix, 1985.

MORAES, Vinícius. Obra poética. Rio de Janeiro: Nova Aguilar, 1968.

MORAES, Vinícius. Site Oficial. http://www.viniciusdemoraes.com.br/.

MORIN, Edgar. O homem e a morte. Portugal: Europa-América, 1988.

SILVA, Rosana Rodrigues. A poesia religiosa de Vinícius de Moraes: gênese de uma poética. Terra roxa e outra terras: revista de estudo literários. Londrina, v.5. Disponível em: http://www.uel.br/cch/pos/letras/terraroxa/g_pdf/vol5/v5_7.pdf . Acesso em: 16 de jun. de 06.

WILSON, Edmund. O castelo de Axel. São Paulo: Cultrix, 1987. 